\title{
Direct detection of nasal Staphylococcus aureus carriage via helicase-dependent isothermal amplification and chip hybridization
}

\author{
Georges C Frech, Denton Munns, Robert D Jenison and Brian J Hicke*
}

\begin{abstract}
Background: The bacterium Staphylococcus aureus constitutes one of the most important causes of nosocomial infections. One out of every three individuals naturally carries $S$. aureus in their anterior nares, and nasal carriage is associated with a significantly higher infection rate in hospital settings. Nasal carriage can be either persistent or intermittent, and it is the persistent carriers who, as a group, are at the highest risk of infection and who have the highest nasal S. aureus cell counts. Prophylactic decolonization of $S$. aureus from patients' noses is known to reduce the incidence of postsurgical infections, and there is a clear rationale for rapid identification of nasal $S$. aureus carriers among hospital patients.
\end{abstract}

Findings: A molecular diagnostic assay was developed which is based on helicase-dependent target amplification and amplicon detection by chip hybridization to a chip surface, producing a visible readout. Nasal swabs from 70 subjects were used to compare the molecular assay against culturing on "CHROMagar Staph aureus" agar plates. The overall relative sensitivity was $89 \%$, and the relative specificity was $94 \%$. The sensitivity rose to $100 \%$ when excluding low-count subjects ( $<100 \mathrm{~S}$. aureus colony-forming units per swab).

Conclusions: This molecular assay is much faster than direct culture and has sensitivity that is appropriate for identification of high-count (>100 S. aureus colony-forming units per swab) nasal S. aureus carriers who are at greatest risk for nosocomial infections.

Keywords: Staphylococcus aureus, Nasal carriage, Molecular diagnostic, Helicase-dependent amplification

\section{Findings \\ Background}

Nosocomial bacterial infections are an important cause of morbidity and mortality, attributable for approximately 100,000 deaths annually in the United States [1]. The Gram-positive bacterial pathogen Staphylococcus aureus is causally involved in a significant fraction of these infections, with about $0.8 \%$ of all US hospital inpatients suffering from a $S$. aureus infection [2]. The anterior nares represent the primary ecological reservoir for S. aureus in humans, with one in three individuals being carriers [3]. Three different nasal carriage patterns have been discerned, with approximately $20 \%$ of the population being persistent carriers, $30-60 \%$ intermittent

\footnotetext{
* Correspondence: bhicke@gbscience.com

Great Basin Corporation, 2441 South 3850 West, Salt Lake City, UT 84120,
} USA

\section{() Biomed Central}

carriers, and the remainder being non-carriers [4]. The quantity of $S$. aureus colony-forming units (CFU) that can be recovered from swabs obtained from carriers' noses varies widely, from single-digits to millions $[5,6]$, and there is a strong association between high cell count and persistent carriage [7-9]. Based on various levels of evidence, it has been suggested that persistent carriers represent a separate group that is distinct from intermittent and non-carriers $[8,10]$.

Colonization of the human nose by $S$. aureus represents a commensal relationship, and carriage is inconsequential to the healthy human host in every-day life. However, S. aureus nasal carriage translates into a three to four fold higher infection rate in hospital settings compared to non-carriers [11-14]. In one population of dialysis patients, persistent nasal $S$. aureus carriers carried a 3.4 times higher risk than intermittent carriers [13]. Prospective and retrospective studies revealed that 
the majority of nosocomially infected nasal carriers suffer from a $S$. aureus strain that is clonally identical to the commensal strain carried in their nose, thereby strongly implicating an endogenous origin [11,14-16].

Topical intranasal mupirocin application provides an effective and safe option for $S$. aureus decolonization and, when used prophylactically, reduces the incidence of postsurgical infections [17]. The strongest evidence so far was provided by a double-blind, placebo-controlled, multicenter trial that used randomized patient groups from multiple hospitals in the Netherlands [16]. The results revealed a 2.4-fold reduction in risk of surgicalsite $S$. aureus infections for the treatment group. The authors concluded that rapid identification of nasal $S$. aureus carriage at the time of hospital admission speeds decolonization and is a critical factor in reducing hospital-associated $S$. aureus infections. Due to the reported emergence of mupirocin resistance, it is prudent to restrict nasal mupirocin application only to patients who are likely to benefit from it [18]. This provides a strong incentive for hospital-based nasal S. aureus screening of patients who will be undergoing an invasive medical procedure, by using a molecular diagnostic test for rapid identification of nasal carrier status and initiation of $S$. aureus decolonization without delay.

Commercially available nasal screening tests generally use either polymerase chain reaction (PCR)-based or microbiological culture-based methods. PCR-based molecular diagnostic tests provide much faster turnaround relative to the lower cost culture-based methods, and the benefit of rapid turnaround has been well established [19]. The commercial PCR assay designs in use identify methicillin-resistant S. aureus (MRSA) [20-23], and they do so by targeting a mobile staphylococcal cassette chromosome (SCC) element referred to as SCCmec [24]. This assay design causes false positive rates that significantly impact MRSA screening efficacy [25-27], in particular in geographic regions where MRSA prevalence is low or on the decrease, and it can also cause false negatives $[28,29]$. We have developed an alternative molecular detection method that targets S. aureus-specific sequences in the thermonuclease (nuc) gene [30,31]. The assay system recapitulates the rapid turnaround time of PCR but at lowered cost, using isothermal amplification coupled to chip-based detection followed by digital camera capture of the chip image [32].

\section{Subjects, materials and methods}

\section{Subjects and nasal swab collection}

Subjects who volunteered to provide nasal swabs for this study were healthy individuals, 39 male and 31 female. Subjects provided written informed consent for their nasal swab samples to be utilized in this study, which was approved by the Great Basin Corporation internal
Ethics Committee. All samples were de-identified. Each sterile media-free Double Swab (BD BBL CultureSwabs 220135) was pre-moistened with $75 \mathrm{uL}$ sterile phosphate buffered saline (PBS) and pre-scored for subsequent facilitated detachment of the polyester tip from its stem. Volunteers were instructed to insert the Double Swab into one of their nostrils and rotate it for at least $15 \mathrm{sec}-$ onds while scrubbing the surface of the anterior nare, and then repeat the same procedure for the second nostril. The swabs were kept at ambient temperature and processed no later than 2 hours after sampling. Swab A was used for microbiological examination and swab B was processed for molecular analysis.

\section{Direct culture}

The head of swab A was detached from its stem, transferred into a tube containing $200 \mathrm{uL} 10 \mathrm{mM}$ Tris (pH 8.8), $10 \mathrm{mM} \mathrm{NaCl}$ (TN-Buffer), and vortexed for $30 \mathrm{sec}-$ onds at maximum setting. This yielded a recoverable volume of approximately $160 \mathrm{uL}$ nasal mucus suspension, and $100 \mathrm{uL}$ thereof was directly plated onto a "BBL CHROMagar Staph aureus" agar plate (Becton Dickenson) which was then incubated at $37^{\circ} \mathrm{C}$ for $18-20$ hours. The samples that gave rise to mauve colonies on plates, indicative of $S$. aureus, were scored as positive by direct culture. The number of mauve colonies per plate was counted exactly (if $<1000$ ) or estimated (if $>1000$ ), and $S$. aureus CFU counts per swab were extrapolated by multiplying with a factor of 1.6.

\section{Preparation of bacterial DNA from nasal swabs}

The head of swab B was detached from its stem, placed into $500 \mathrm{uL}$ TN-Buffer, and vortexed for 30 seconds at maximum setting. The sample was then centrifuged for 10 minutes at $14,000 \times \mathrm{g}$ at ambient temperature. The supernatant was discarded and the pellet re-suspended in $100 \mathrm{uL}$ TN-Buffer containing $0.5 \mathrm{U} / \mathrm{uL}$ achromopeptidase (Wako Chemicals, Richmond, VA). The mixture was incubated for 15 minutes at $37^{\circ} \mathrm{C}$, followed by 5 minutes at $98^{\circ} \mathrm{C}$. Two $5 \mathrm{uL}$ aliquots were used in replicate Helicase-dependent amplification reactions, and the rest was stored frozen at $-20^{\circ} \mathrm{C}$.

\section{Asymmetric helicase-dependent amplification (HDA)}

Amplification reactions were set up according to conditions as provided by the IsoAmp II Universal tHDA Kit (BioHelix, Beverly, MA). For each individual HDA reaction, $5 \mathrm{uL}$ of nasal mucus lysate was first mixed with 15 $\mu \mathrm{L}$ of Dilution Buffer, giving rise to concentrations of $20 \mathrm{mM}$ Tris- $\mathrm{HCl}, \mathrm{pH} 8.8,10 \mathrm{mM} \mathrm{KCl}, 7.7 \mathrm{mM} \mathrm{MgSO}_{4}$, $40 \mathrm{mM} \mathrm{NaCl}, 5 \mathrm{mg} / \mathrm{mL} \mathrm{BSA}$, and $0.02 \%$ Tween 20. This was then added to $20 \mathrm{uL} 2 \mathrm{x}$ HDA-Mix $20 \mathrm{mM}$ Tris$\mathrm{HCl}, \mathrm{pH}$ 8.8, $40 \mathrm{mM} \mathrm{NaCl}, 0.02 \%$ Triton X-100, 0.4x EvaGreen (Biotium, Hayward, CA), $6.8 \mathrm{mM}$ dATP, 
$0.8 \mathrm{mM}$ dCTP, $0.8 \mathrm{mM}$ dGTP, $0.8 \mathrm{mM}$ dTTP, $10 \mathrm{ng} / \mathrm{uL}$ uvrD Thermostable DNA Helicase, 1.6 U/uL GST Polymerase Large Fragment, 4 ng/uL ET SSB (Extreme Thermostable Single-Stranded DNA Binding Protein), and diluted RNase H2 (Great Basin Corp), 600 nM Forward primer, and $800 \mathrm{nM}$ biotinylated Reverse primer (5'Biotin-TEG) $\}$ and mixed thoroughly in a well of a LightCycler 480 Multiwell Plate 96 (Roche Diagnostics, Indianapolis, IN). The multiwell plate was transferred into a LightCycler 480 instrument and incubated for 60 minutes using an isothermal temperature profile set to $65^{\circ} \mathrm{C}$.

Primers were ordered from IDT, and each primer contained a single ribo-nucleotide close to the 3 ' end as well as a 3' blocking group, creating "hot start-like" conditions. Deblocking requires that primers be annealed to the target DNA sequence, resulting in cleavage by RNase $\mathrm{H} 2$ at temperatures above $50^{\circ} \mathrm{C}$, followed by polymerase extension. Primer artifact is suppressed because the RNase H2 is inactive at low temperature. The nucleotide sequences of the amplification primers were 5' -TGGTAGAAAAT GCAAAGAAAATTGAAGTC[rG]AGTT-3' for the Forward primer and 5'- TCCATCAGCATAAATATACG CTAAGCCA[rC]GTCC-3' for the Reverse primer, giving rise to an amplification product size of 95 base pairs.

\section{Chip preparation and hybridization}

Crystalline silicon wafers were coated with the polymer amino functional T-structure poly-dimethylsiloxane (TSPS, United Chemical Technologies, Bristol, PA) and cured at $150^{\circ} \mathrm{C}$ for 24 hours. The TSPS coated wafer was further prepared by soaking in a $50 \mathrm{mg} / \mathrm{L}$ solution of poly (lys-phe) in 1x phosphate-buffered saline (PBS, $\mathrm{pH}$ 6) containing $2 \mathrm{M} \mathrm{NaCl}$ overnight at room temperature. Next, the poly (lys-phe) coated wafer was washed and soaked in $10 \mu \mathrm{M}$ succimidyl-4-formyl benzoate (SFB, Sigma-Aldrich, St. Louis, MO) for 2 hours at room temperature, washed thoroughly with water, dried with a stream of nitrogen, and stored at room temperature.

Capture probes were synthesized by IDT and contain an internal 18-atom hexa-ethyleneglycol spacer connected to a reactive 5'-moiety (I-Linker) that couples to the aldehyde-functionalized chip surface. Probes in Spotting Buffer $(0.1 \mathrm{M}$ phosphate buffer $\mathrm{pH} 8.0,10 \%$ glycerol) were spotted $(75 \mathrm{~nL})$ on the surface of the SFBcoated silicon wafer. A biotin-labeled $[\mathrm{dA}]_{18}$ detection control (DC) probe was spotted at $50 \mathrm{nM}$, and a hybridization control $(\mathrm{HC})$ capture probe was also spotted at $50 \mathrm{nM}$ (complementary to biotinylated detection probe present in bybridization buffer). To orient chips for subsequent processing a fiducial marker (carboxylated polystyrene microspheres) was also printed. The $S$. aureus nuc amplicon-specific capture probe was spotted at $400 \mathrm{nM}$ concentration, and its DNA sequence was
5'-GACAAAGGTCAAAGAACTGA-3'. After incubating for 2 hours, the wafers were washed with $0.1 \%$ SDS, dried, and scribed into individual $6.7 \mathrm{~mm}$ square chips before use.

For chip hybridization, $20 \mu \mathrm{L}$ of HDA amplicon was added to $80 \mu \mathrm{L}$ of hybridization buffer (5x SSC, $0.05 \%$ Tween 20, 0.5\% alkaline-treated casein (ATC), $1 \mathrm{nM}$ hybridization control ( $\mathrm{HC}$ ) biotinylated detection probe) and pre-warmed in a heat block at $65^{\circ} \mathrm{C}$ for 5 minutes. The hybridization mixture was then transferred onto chips in a 96-well plate that had been prewarmed to $53^{\circ}$ $\mathrm{C}$, and hybridization was allowed to proceed for $5 \mathrm{~min}$ utes at $53^{\circ} \mathrm{C}$. Solution was removed, and the chips were washed 3 times with WashBuffer-A (0.1x SSC, $0.1 \%$ SDS), then washed 3 times with WashBuffer-B (0.1x SSC, $0.05 \%$ Tween 20 ), before adding $100 \mu \mathrm{L}$ of conjugate solution $(1 \mu \mathrm{g} / \mathrm{mL}$ anti biotin antibody/HRP in $5 \mathrm{x}$ SSC, $10 \%$ fetal calf serum, $0.5 \%$ ATC) and incubating at room temperature for 4 minutes. Chips were then washed 3 times with WashBuffer-B before addition of $100 \mu \mathrm{L}$ Membrane 3,3',5,5'-Tetramethylbenzidine (TMB, BioFX Laboratories, Eden Prairie, MN) to the chip surface and incubation at room temperature for 4 minutes. Chips were washed with water and methanol, air-dried, and then imaged.

\section{Discrepancy resolution analyses}

Nasal swab samples that gave rise to a negative result by direct culture but a positive result by the molecular assay were followed up by a repeat of the HDA and chip hybridization, using fresh aliquots of the original nasal swab lysates. Furthermore, HDA discordant positives were followed up by PCR amplification (Roche LightCycler 480) using the nuc gene amplification primers published by Brakstad and coworkers [31]. A product band of the correct size was verified by polyacrylamide gel electrophoresis. In addition, volunteers whose nasal swabs produced molecular assay discordant positives were asked to provide follow-up nasal Double Swabs, and these were processed as described above for direct culture as well as molecular assay analysis.

Volunteers whose nasal swabs gave rise to a positive result by direct culture but a negative result by the molecular assay, were asked to provide a follow-up nasal swab a few weeks later. These follow-up swabs were processed by direct culturing as described above.

\section{Results and discussion}

\section{Analytical assay performance}

The molecular diagnostic assay described in this study is based on isothermal helicase-dependent amplification (HDA) [33] of Staphylococcus aureus-specific DNA sequences, derived from the thermonuclease gene nuc, followed by hybridization of the biotinylated amplification product to a $n u c$-specific capture probe 
immobilized on silicon chips. To define assay sensitivity, pooled nasal mucus was spiked with dilutions of $S$. aureus cells, and the chip could detect as few as 2 CFU per HDA reaction, which extrapolates to $40 \mathrm{CFU}$ per swab (data not shown). This indicates that the protocol developed for this study efficiently enriched and lysed $S$. aureus cells present in nasal mucus, making the bacterial genomic DNA available for amplification. A panel of $21 \mathrm{~S}$. aureus strains was then used to test reactivity of the $n u c$ gene HDA primers and hybridization probe. All 21 strains gave rise to positive HDA and chip hybridization signals (Table 1). To verify that the assay detects only Staphylococcus aureus, a panel of prokaryotic and eukaryotic organisms was examined. No positive $n u c$ amplicon signal was observed for the 8 other staphylococcal species or the 17 additional bacterial and eukaryotic organisms that were tested (Table 2). These results are consistent with previous studies establishing that the nuc gene contains $S$. aureus-specific sequences $[30,31]$ and with a recently published study in which the nuc gene was present in 1781 of 1783 S. aureus isolates (99.9\% sensitivity) [34].

\section{S. aureus-positive samples}

A total of 70 volunteers were enrolled for this nasal $S$. aureus detection study. Of these, 36 individuals were culture-positive on "CHROMagar Staph aureus" plates, with a range between 3 and more than 100,000 CFU per swab (Table 3). In comparison to direct culture, the molecular diagnostic assay had a relative sensitivity of $89 \%$ (Table 4). Using a cutoff of $100 \mathrm{~S}$. aureus CFU per swab, the samples were stratified into "high-count" and "lowcount" groups. This cutoff was selected originally based on data provided in Figure 2 from the article by Nouwen et al. [7], which indicated that swabs with more than $100 \mathrm{CFU}$ are significantly more likely to originate from persistent carriers than from intermittent carriers. More recently published results revealed that 20/21 samples from persistent carriers were associated with nasal $S$. aureus loads of $>100 \mathrm{CFU}$ per swab, and 13/14 samples from non-persistent carriers were associated with loads of $\leq 100 \mathrm{CFU}$ [9], further validating our selection of this cutoff value. Of the 36 nasal $S$. aureus carriers identified in this study, 29 were classified into the high-count group. All of these 29 individuals were positive by the molecular assay (Table 3), and for this subgroup the concordance between the molecular assay and direct culture was $100 \%$ (Table 5). Seven samples had fewer than $100 \mathrm{~S}$. aureus CFU per swab (Table 3), four of which were negative by the molecular assay. This is not surprising since these samples contained S. aureus CFU numbers near or below the lower limit of detection. Two discrepant samples were

\section{Table 1 Staphylococcus aureus strains tested for sensitivity of amplification primer set and detection probe}

\begin{tabular}{|c|c|c|c|}
\hline Organism & ATCC number & Other designations & Molecular assay \\
\hline S. aureus subsp. aureus Rosenbach & 6538 & FDA 209 & positive \\
\hline S. aureus subsp. aureus Rosenbach & 14993 & $\mathrm{PCl} 1217[21 \mathrm{~J}]$ & positive \\
\hline S. aureus subsp. aureus Rosenbach & 25923 & Seattle 1945 & positive \\
\hline S. aureus subsp. aureus Rosenbach & 33591 & 328 & positive \\
\hline S. aureus subsp. aureus Rosenbach & 33592 & 1063 & positive \\
\hline S. aureus subsp. aureus Rosenbach & 43300 & $F-182$ & positive \\
\hline S. aureus subsp. aureus Rosenbach & BAA-1720 & & positive \\
\hline S. aureus Rosenbach & BAA-1749 & $96: 308$ & positive \\
\hline S. aureus Rosenbach & BAA-1764 & 7031 & positive \\
\hline S. aureus Rosenbach & BAA-1765 & $102-04$ & positive \\
\hline S. aureus subsp. aureus Rosenbach & $\mathrm{BAA}-42$ & HDE288 & positive \\
\hline S. aureus & & ANS46 & positive \\
\hline S. aureus subsp. aureus COL & & STAAC, 93062 & positive \\
\hline S. aureus & & HDG2 & positive \\
\hline S. aureus & & MA14 & positive \\
\hline S. aureus & & MA15 & positive \\
\hline S. aureus & & MA6 & positive \\
\hline S. aureus & & MA8 & positive \\
\hline S. aureus & & MSH7 & positive \\
\hline S. aureus subsp. aureus MW2 & & STAAW, 196620 & positive \\
\hline S. aureus & & WIS & positive \\
\hline
\end{tabular}

Isolated microbial colonies were suspended in TN-Buffer, lysed by incubation with achromopeptidase followed by boiling, and the equivalent of in the order of $10^{6}$ cells was added to each HDA molecular assay reaction. 
Table 2 Species tested for specificity of amplification primer set and detection probe

\begin{tabular}{|c|c|c|c|}
\hline Organism & Source of isolate & Characteristics & Molecular assay \\
\hline S. schleiferi & ATCC \# 43808 & Coagulase-positive & negative \\
\hline S. capitis & ATCC \# 35661 & Coagulase-negative & negative \\
\hline S. epidermidis & ATCC \# 12228 & Coagulase-negative & negative \\
\hline S. haemolyticus & ATCC \# 29970 & Coagulase-negative & negative \\
\hline S. hominis & ATCC \# 700236 & Coagulase-negative & negative \\
\hline S. lugdunensis & ATCC \# 43809 & Coagulase-negative & negative \\
\hline S. saprophyticus & ATCC \# 15305 & Coagulase-negative & negative \\
\hline S. succinus & ATCC \# 700337 & Coagulase-negative & negative \\
\hline Bacillus subtilis & ATCC \# 23859 & gram-positive & negative \\
\hline Clostridium difficile & ATCC \# BAA-1382 & gram-positive & negative \\
\hline Enterococcus faecalis & ATCC \# 700802 & gram-positive & negative \\
\hline Enterococcus faecium & ATCC \# 51559 & gram-positive & negative \\
\hline Micrococcus luteus & ATCC \# 10240 & gram-positive & negative \\
\hline Mycobacterium abscessus & ATCC \# 19977 & gram-positive & negative \\
\hline Streptococcus agalactiae & ATCC \# 13813 & gram-positive & negative \\
\hline Streptococcus pneumoniae & ATCC \# 6308 & gram-positive & negative \\
\hline Acinetobacter baumannii & ATCC \# 17978 & gram-negative & negative \\
\hline Citrobacter freundii & ATCC \# 8090 & gram-negative & negative \\
\hline Escherichia coli & ATCC \# 4157 & gram-negative & negative \\
\hline Klebsiella pneumoniae & ATCC \# 13883 & gram-negative & negative \\
\hline Neisseria gonorrhoeae & ATCC \# 53420 & gram-negative & negative \\
\hline Pseudomonas putida & ATCC \# 47054 & gram-negative & negative \\
\hline Candida albicans & ATCC \# 18804 & & negative \\
\hline Saccharomyces cerevisiae & Strain S288C & & negative \\
\hline Homo sapiens & Roche Cat. \#11691112001 & & negative \\
\hline
\end{tabular}

Isolated microbial colonies were suspended in TN-Buffer (see Materials and Methods section), lysed by incubation with achromopeptidase and/or boiling, and the equivalent of in the order of $10^{6}$ cells (or $20 \mathrm{ng}$ purified yeast DNA or $80 \mathrm{ng}$ human DNA) was added to each HDA molecular assay reaction.

confirmed as nuc-negative (Table 3) by PCR analysis using previously published nuc gene primers [31].

Individuals who carry low numbers of $S$. aureus cells are more likely to be intermittent rather than persistent nasal carriers [7-9]. Three volunteers whose nasal swab samples gave rise to discrepant results (\#31, \#33, \#36, Table 3) were able to provide a follow-up swab a few weeks later. Two of the three follow-up swabs turned up negative on direct culture, classifying these two volunteers as intermittent $S$. aureus carriers (\#33, \#36, Table 3).

Table 3 Nasal swab samples giving rise to mauve colonies on "CHROMagar S. aureus" agar plates

\begin{tabular}{lllll}
\hline$\#$ & Initial Swab: CFU/Swab & Molecular assay & Follow-up PCR & Follow-up Swab: CFU/Swab \\
\hline $\mathbf{1 - 2 7}$ & $\mathbf{2 1 0 0 , 0 0 0}$ to $>\mathbf{2 , 0 0 0}$ & All Positive & & \\
\hline $\mathbf{2 8}$ & $\mathbf{1 1 5 2}$ & Positive & & \\
\hline $\mathbf{2 9}$ & $\mathbf{3 8 7}$ & Positive & & \\
\hline 30 & 38 & Positive & ND & 0 \\
\hline 31 & 27 & Negative & ND \\
\hline 32 & 8 & Positive & & \\
\hline 33 & 6 & Negative & ND \\
\hline 34 & 5 & Positive & Negative & 0 \\
\hline 35 & 3 & Negative & Negative &
\end{tabular}

Samples are sorted by CFU/Swab. The 29 samples giving rise to $>100$ mauve colonies per plate were classified as "high-count" and are indicated in bold. CFU: Colony Forming Units. ND: Not Done. 
Table 4 Comparison of the molecular assay results to the direct culture method

\begin{tabular}{lllll}
\hline & & \multicolumn{2}{c}{ Direct culture } & \multirow{2}{*}{ Total } \\
\cline { 3 - 4 } & & Positive & Negative & \\
\hline Molecular Assay & Positive & 32 & 2 & 34 \\
\hline & Negative & 4 & 32 & 36 \\
\hline Sensitivity: & Total & 36 & 34 & 70 \\
\hline Specificity: & $89 \%$ & & & \\
\hline
\end{tabular}

\section{S. aureus-negative samples}

Of the 70 volunteers, 34 were culture-negative. Two of these 34 samples gave rise to a positive result by the molecular assay, which translates into a relative specificity of $94 \%$ (Table 4). Both samples remained positive upon repeated molecular analysis. Follow-up Double Swabs were subsequently obtained from the two volunteers. Swabs from both individuals were again molecular assay-positive, and individual I was again culturenegative while individual II yielded $3 \mathrm{CFU}$, indicating that individual II was a low-count carrier. The samples from both volunteers were confirmed as $n u c$-positive by PCR analysis [31].

Resolution of the discrepancies between the identification of $S$. aureus by nuc gene amplification versus direct microbiological culture will require further analyses. While the microbiological method chosen for this study, direct culturing on "CHROMagar Staph aureus" chromogenic medium, is characterized by its simplicity as well as excellent specificity, the sensitivity of this method is not $100 \%$. Among $310 \mathrm{~S}$. aureus-positive clinical specimens, CHROMagar Staph aureus was $95.5 \%$ sensitive [35]. Therefore, one would expect one or two of the 34 negative samples in the present study to be falsely negative. Alternatively, it is conceivable that swabs obtained from certain low-count individuals may contain mostly dead cells that would go undetected by culture, since this method relies upon the presence of live cells. Discrepancy resolution might be achieved by the amplification and sequencing of the rpoB gene which allows for accurate differentiation of staphylococcal isolates at the species and subspecies level [36]. However, since the nasal environment is known to contain a mixture of multiple bacterial species [37], sequencing of amplification products obtained from nasal swab lysates

Table 5 Stratification of S. aureus-positive samples: high-count group only (>100 CFU/swab)

\begin{tabular}{lll}
\hline & \multicolumn{2}{c}{ Number of samples } \\
\cline { 2 - 3 } & Positives & Negatives \\
\hline Direct Culture & 29 & 0 \\
\hline Molecular Assay & 29 & 0 \\
\hline Concordance: & $100 \%$ & \\
\hline
\end{tabular}

would require sequence analysis of large numbers of clones.

\section{Prevalence of S. aureus nasal carriage}

The fraction of volunteers in this study who were positive for nasal carriage of S. aureus (36-38/70; 51-54\%) is higher than the $32 \%$ prevalence that was reported by the large ( 10,000 subjects) US National Health and Nutrition Examination Survey conducted between 2001 and 2002 [3]. Notably, nasal S. aureus carriage clusters in families [38], and the higher prevalence observed in the present study could be explained by the fact that the volunteer group did not represent a random population sample but contained a significant number of biological relatives. Furthermore, the volunteer group for this study contained more males than females, and the $S$. aureus nasal carriage prevalence is higher among males than females [3]. In addition, the dry climate in Utah, where this study was conducted, is associated with higher rates of nose bleeding which is correlated with nasal S. aureus carriage [39] and appears to be directly mediated by the presence of hemoglobin [40].

\section{Conclusions}

The molecular diagnostic assay described in this study combines helicase-dependent isothermal amplification of a $S$. aureus species-specific DNA sequence out of nasal swab lysate with chip-based detection by hybridization and an eye-visible readout. In the present study involving nasal swabs from 70 volunteers, this molecular assay showed $100 \%$ sensitivity in identifying those individuals who are high-count nasal carriers of $S$. aureus ( $>100$ CFU per swab). It is these individuals who have increased risk of infection after invasive procedures in hospitals, and therefore need to be rapidly identified and de-colonized prior to an invasive procedure. The assay concept presented here lends itself to incorporation into an automated molecular diagnostic platform for rapid identification of nasal S. aureus carriers in hospital settings.

Updated commercial PCR strategies can incorporate mecA gene amplification to mitigate the problem of false positive results in so-called "empty cassette" strains that result from incomplete SCCmec cassette excision (Arbefeville SS et al 2012. J Clin Micro 49:2996-2999).

\section{Competing interests}

All authors were employed by the company Great Basin Corporation.

\section{Authors' contributions}

GCF wrote the manuscript, participated in the design of the study, acquisition of data, and directed the analysis and interpretation of the data. DM was responsible for data acquisition and participated in the analysis and interpretation of the data. RDJ originated the assay concept and critically revised the manuscript. BJH participated in the design and conception of the study, and critically revised the manuscript. All authors read and approved the final manuscript. 
Received: 2 April 2012 Accepted: 6 August 2012

Published: 11 August 2012

\section{References}

1. Taubes G: The bacteria fight back. Science 2008, 321:356-361.

2. Noskin GA, Rubin RJ, Schentag JJ, Kluytmans J, Hedblom EC, Smulders M, Lapetina E, Gemmen E: The burden of Staphylococcus aureus infections on hospitals in the United States: an analysis of the 2000 and 2001 Nationwide Inpatient Sample Database. Arch Intern Med 2005, 165:1756-1761.

3. Kuehnert MJ, Kruszon-Moran D, Hill HA, McQuillan G, McAllister SK, Fosheim G, McDougal LK, Chaitram J, Jensen B, Fridkin SK, Killgore G, Tenover FC: Prevalence of Staphylococcus aureus nasal colonization in the United States, 2001-2002. J Infect Dis 2006, 193:172-179.

4. Wertheim HF, Melles DC, Vos MC, van Leeuwen W, van Belkum A, Verbrugh $H A$, Nouwen $J$ : The role of nasal carriage in Staphylococcus aureus infections. Lancet Infect Dis 2005, 5:751-762.

5. White A: Quantitative studies of nasal carriers of staphylococci among hospitalized patients. J Clin Invest 1961, 40:23-30.

6. Mermel LA, Eells SJ, Acharya MK, Cartony JM, Dacus D, Fadem S, Gay EA, Gordon S, Lonks JR, Perl TM, McDougal LK, McGowan JE, Maxey G, Morse D, Tenover FC: Quantitative analysis and molecular fingerprinting of methicillin-resistant Staphylococcus aureus nasal colonization in different patient populations: a prospective, multicenter study. Infect Control Hosp Epidemiol 2010, 31:592-597.

7. Nouwen JL, Ott A, Kluytmans-Vandenbergh MF, Boelens HA, Hofman A, van Belkum A, Verbrugh HA: Predicting the Staphylococcus aureus nasal carrier state: derivation and validation of a "culture rule". Clin Infect Dis 2004, 39:806-811.

8. van Belkum A, Verkaik NJ, de Vogel CP, Boelens HA, Verveer J, Nouwen JL, Verbrugh HA, Wertheim HF: Reclassification of Staphylococcus aureus nasal carriage types. J Infect Dis 2009, 199:1820-1826.

9. Verhoeven PO, Grattard F, Carricajo A, Lucht F, Cazorla C, Garraud O, Pozzetto B, Berthelot P: Quantification by Real-Time PCR Assay of Staphylococcus aureus Load: a Useful Tool for Rapidly Identifying Persistent Nasal Carriers. J Clin Microbiol 2012, 50:2063-2065.

10. Nouwen JL, Fieren MW, Snijders S, Verbrugh HA, van Belkum A: Persistent (not intermittent) nasal carriage of Staphylococcus aureus is the determinant of CPD-related infections. Kidney Int 2005, 67:1084-1092

11. Kluytmans JA, Mouton JW, ljzerman EP, Vandenbroucke-Grauls CM, Maat AW, Wagenvoort JH, Verbrugh HA: Nasal carriage of Staphylococcus aureus as a major risk factor for wound infections after cardiac surgery. I Infect Dis 1995, 171:216-219.

12. Luzar MA, Coles GA, Faller B, Slingeneyer A, Dah GD, Briat C, Wone C, Knefati Y, Kessler M, Peluso F: Staphylococcus aureus nasal carriage and infection in patients on continuous ambulatory peritoneal dialysis. $N$ Engl J Med 1990, 322:505-509.

13. Nouwen J, Schouten J, Schneebergen P, Snijders S, Maaskant J, Koolen M, van Belkum A, Verbrugh HA: Staphylococcus aureus carriage patterns and the risk of infections associated with continuous peritoneal dialysis. $J$ Clin Microbiol 2006, 44:2233-2236.

14. Wertheim HF, Vos MC, Ott A, van Belkum A, Voss A, Kluytmans JA, van Keulen PH, Vandenbroucke-Grauls CM, Meester MH, Verbrugh HA: Risk and outcome of nosocomial Staphylococcus aureus bacteraemia in nasal carriers versus non-carriers. Lancet 2004, 364:703-705.

15. von Eiff C, Becker K, Machka K, Stammer H, Peters G: Nasal carriage as a source of Staphylococcus aureus bacteremia. N Engl I Med 2001, 344:11-16.

16. Bode $L G$, Kluytmans JA, Wertheim HF, Bogaers D, Vandenbroucke-Grauls CM, Roosendaal R, Troelstra A, Box AT, Voss A, van der Tweel I, van Belkum $A$, Verbrugh HA, Vos MC: Preventing surgical-site infections in nasal carriers of Staphylococcus aureus. N Engl J Med 2010, 362:9-17.

17. van Rijen MM, Bonten M, Wenzel RP, Kluytmans JA: Intranasal mupirocin for reduction of Staphylococcus aureus infections in surgical patients with nasal carriage: a systematic review. J Antimicrob Chemother 2008, 61:254-261.

18. Caffrey AR, Quilliam BJ, LaPlante KL: Risk factors associated with mupirocin resistance in meticillin-resistant Staphylococcus aureus.J Hosp Infect 2010, 76:206-210
19. Paule SM, Pasquariello AC, Hacek DM, Fisher AG, Thomson RB Jr, Kaul KL, Peterson LR: Direct detection of Staphylococcus aureus from adult and neonate nasal swab specimens using real-time polymerase chain reaction. J Mol Diagn 2004, 6:191-196.

20. Rossney AS, Herra CM, Fitzgibbon MM, Morgan PM, Lawrence MJ, O'Connell B: Evaluation of the IDI-MRSA assay on the SmartCycler real-time PCR platform for rapid detection of MRSA from screening specimens. Eur J Clin Microbiol Infect Dis 2007, 26:459-466.

21. Rossney AS, Herra CM, Brennan GI, Morgan PM, O'Connell B: Evaluation of the Xpert methicillin-resistant Staphylococcus aureus (MRSA) assay using the GeneXpert real-time PCR platform for rapid detection of MRSA from screening specimens. J Clin Microbiol 2008, 46:3285-3290.

22. Wolk DM, Picton E, Johnson D, Davis T, Pancholi P, Ginocchio CC, Finegold S, Welch DF, de Boer M, Fuller D, Solomon MC, Rogers B, Mehta MS, Peterson LR: Multicenter evaluation of the Cepheid Xpert methicillinresistant Staphylococcus aureus (MRSA) test as a rapid screening method for detection of MRSA in nares. J Clin Microbiol 2009, 47:758-764.

23. Peterson LR, Liesenfeld O, Woods CW, Allen SD, Pombo D, Patel PA, Mehta MS, Nicholson B, Fuller D, Onderdonk A: Multicenter evaluation of the LightCycler methicillin-resistant Staphylococcus aureus (MRSA) advanced test as a rapid method for detection of MRSA in nasal surveillance swabs. J Clin Microbiol 2010, 48:1661-1666.

24. Katayama Y, Ito T, Hiramatsu K: A new class of genetic element, staphylococcus cassette chromosome mec, encodes methicillin resistance in Staphylococcus aureus. Antimicrob Agents Chemother 2000, 44:1549-1555.

25. Huletsky A, Giroux R, Rossbach V, Gagnon M, Vaillancourt M, Bernier M, Gagnon F, Truchon K, Bastien M, Picard FJ, van Belkum A, Ouellette M, Roy PH, Bergeron MG: New real-time PCR assay for rapid detection of methicillin-resistant Staphylococcus aureus directly from specimens containing a mixture of staphylococci. J Clin Microbiol 2004, 42:1875-1884.

26. Herdman MT, Wyncoll D, Halligan E, Cliff PR, French G, Edgeworth JD: Clinical application of real-time PCR to screening critically ill and emergency-care surgical patients for methicillin-resistant Staphylococcus aureus: a quantitative analytical study. J Clin Microbiol 2009, 47:4102-4108.

27. Stamper PD, Louie L, Wong H, Simor AE, Farley JE, Carroll KC: Genotypic and phenotypic characterization of methicillin-susceptible Staphylococcus aureus isolates misidentified as methicillin-resistant Staphylococcus aureus by the BD GeneOhm MRSA assay. J Clin Microbiol 2011, 49:1240-1244.

28. Bartels MD, Boye K, Rohde SM, Larsen AR, Torfs H, Bouchy P, Skov R, Westh $\mathrm{H}$ : A common variant of staphylococcal cassette chromosome mec type IVa in isolates from Copenhagen, Denmark, is not detected by the BD GeneOhm methicillinresistant Staphylococcus aureus assay. J Clin Microbiol 2009, 47:1524-1527.

29. García-Álvarez L, Holden MT, Lindsay H, Webb CR, Brown DF, Curran MD, Walpole E, Brooks K, Pickard DJ, Teale C, Parkhill J, Bentley SD, Edwards GF, Girvan EK, Kearns AM, Pichon B, Hill RL, Larsen AR, Skov RL, Peacock SJ, Maskell DJ, Holmes MA: Meticillin-resistant Staphylococcus aureus with a novel mecA homologue in human and bovine populations in the UK and Denmark: a descriptive study. Lancet Infect Dis 2011, 11:595-603.

30. Liebl W, Rosenstein R, Götz F, Schleifer KH: Use of staphylococcal nuclease gene as DNA probe for Staphylococcus aureus. FEMS Microbiol Lett 1987, 44:179-184

31. Brakstad OG, Aasbakk K, Maeland JA: Detection of Staphylococcus aureus by polymerase chain reaction amplification of the nuc gene. $J$ Clin Microbiol 1992, 30:1654-1660.

32. Hicke B, Pasko C, Groves B, Ager E, Corpuz M, Frech G, Munns D, Smith W, Warcup A, Denys G, Ledeboer NA, Lindsey W, Owen C, Rea L, Jenison R: Automated Detection of Toxigenic Clostridium difficile in Clinical Samples: Isothermal tcdB Amplification Coupled to Array-based Detection. J Clin Microbiol 2012, : [Epub ahead of print].

33. An L, Tang W, Ranalli TA, Kim HJ, Wytiaz J, Kong H: Characterization of a thermostable UvrD helicase and its participation in helicase-dependent amplification. J Biol Chem 2005, 280:28952-28958.

34. Fosheim GE, Nicholson AC, Albrecht VS, Limbago BM: Multiplex real-time PCR assay for detection of methicillin-resistant Staphylococcus aureus and associated toxin genes. J Clin Microbiol 2011, 49:3071-3073.

35. Gaillot O, Wetsch M, Fortineau N, Berche P: Evaluation of CHROMagar Staph. aureus, a new chromogenic medium, for isolation and 
presumptive identification of Staphylococcus aureus from human clinical specimens. J Clin Microbiol 2000, 38:1587-1591.

36. Mellmann A, Becker K, von Eiff C, Keckevoet U, Schumann P, Harmsen D: Sequencing and staphylococci identification. Emerg Infect Dis 2006, 12:333-336

37. Frank DN, Feazel LM, Bessesen MT, Price CS, Janoff EN, Pace NR: The human nasal microbiota and Staphylococcus aureus carriage. PLOS One 2010, 5:e10598.

38. Noble WC, Valkenburg HA, Wolters CH: Carriage of Staphylococcus aureus in random samples of a normal population. J Hyg (Lond) 1967, 65:567-573.

39. Whymark AD, Crampsey DP, Fraser L, Moore P, Williams C, Kubba H: Childhood epistaxis and nasal colonization with Staphylococcus aureus. Otolaryngol Head Neck Surg 2008, 138:307-310.

40. Pynnonen M, Stephenson RE, Schwartz K, Hernandez M, Boles BR Hemoglobin Promotes Staphylococcus aureus Nasal Colonization. PLoS Pathog 2011, 7:e1002104.

doi:10.1186/1756-0500-5-430

Cite this article as: Frech et al:: Direct detection of nasal Staphylococcus aureus carriage via helicase-dependent isothermal amplification and chip hybridization. BMC Research Notes 2012 5:430.

\section{Submit your next manuscript to BioMed Central and take full advantage of:}

- Convenient online submission

- Thorough peer review

- No space constraints or color figure charges

- Immediate publication on acceptance

- Inclusion in PubMed, CAS, Scopus and Google Scholar

- Research which is freely available for redistribution 